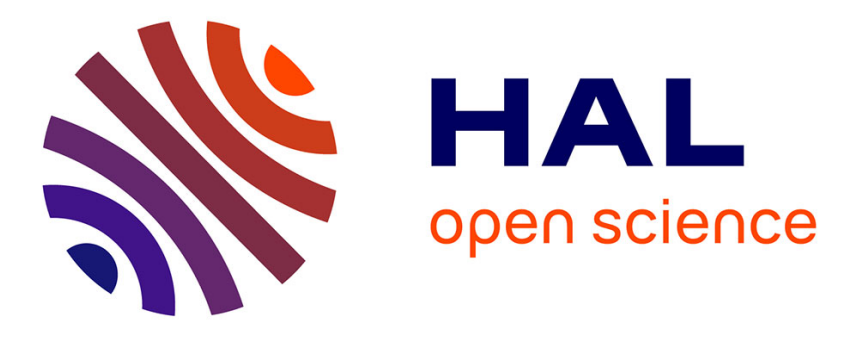

\title{
Girls Who ... Do Scratch a First Round with the Essence Kernel
}

Cassandra Balland, Néné Satorou Cissé, Louise Hergoualc’h, Gwendoline Kervot, Audrey Lidec, Alix Machard, Lisa Ribaud-Le Cann, Constance Rio, Maelle Sinilo, Valérie Dantec, et al.

\section{To cite this version:}

Cassandra Balland, Néné Satorou Cissé, Louise Hergoualc'h, Gwendoline Kervot, Audrey Lidec, et al.. Girls Who . . . Do Scratch a First Round with the Essence Kernel. 2017 IEEE 30th Conference on Software Engineering Education and Training (CSEE\&T), Nov 2017, Savannah, France. 10.1109/CSEET.2017.48 . hal-01756185

\section{HAL Id: hal-01756185 \\ https://hal.univ-brest.fr/hal-01756185}

Submitted on 3 Apr 2018

HAL is a multi-disciplinary open access archive for the deposit and dissemination of scientific research documents, whether they are published or not. The documents may come from teaching and research institutions in France or abroad, or from public or private research centers.
L'archive ouverte pluridisciplinaire HAL, est destinée au dépôt et à la diffusion de documents scientifiques de niveau recherche, publiés ou non, émanant des établissements d'enseignement et de recherche français ou étrangers, des laboratoires publics ou privés. 


\title{
Girls who... do Scratch
}

\author{
A first round with the Essence kernel
}

\author{
Cassandra Balland ${ }^{1}$, Néné Satorou Cissé ${ }^{1}$, Louise \\ Hergoualc' ${ }^{1}$, Gwendoline Kervot ${ }^{1}$, Audrey Lidec ${ }^{1}$, \\ Alix Machard ${ }^{1}$, Lisa Ribaud-Le Cann ${ }^{2}$, \\ Constance Rio ${ }^{1}$, Maelle Sinilo ${ }^{1}$ \\ ${ }^{1}$ Bachelor of Science, ${ }^{2}$ Master of Psychology \\ Université de Bretagne Occidentale \\ Brest, France \\ \{firstname.lastname\}@etudiant.univ-brest.fr
}

\author{
Valérie Dantec ${ }^{1}$, Catherine Dezan ${ }^{3}$, Cyrielle Feron ${ }^{2}$, \\ Claire François ${ }^{1}$, Chabha Hireche ${ }^{3}$, Arwa Khannoussi ${ }^{3}$, \\ Vincent Ribaud ${ }^{3}$ \\ ${ }^{1}$ SIAME, Université de Bretagne Occidentale \\ ${ }^{2}$ Lab-STICC, team MOCS, ENSTA Bretagne \\ ${ }^{3}$ Lab-STICC, team MOCS, UBO \\ Brest, France \\ \{firstname.lastname\}@univ-brest.fr
}

\begin{abstract}
Girls who..." is an education system belonging to the French national program "Accompanying in Science and Technology in the Primary School" (ASTEP). "Girls who..." is a girl network that develops and maintains an facility called the factory, addressing a double goal: setting an example of science performed by women and foster science and technology in elementary schools. Scratch is an open-source environment for multimedia creation intended to young people from 8 to 16 years old. The factory hosts Scratch learning sequences, designed and taught by "girls who..." Essence yields an actionable kernel of seven alphas, each of them going through several states of growing health. Alphas assessment let see a system from different viewpoints: opportunity, stakeholder, requirement, software system, work, team and way-of-working. It gave us a clear vision of the project state and raised critical weaknesses of the facility.
\end{abstract}

Keywords—Scratch; gender equality; elementary school

\section{INTRODUCTION}

"Girls who..." is a facility intended to disseminate Scratch in elementary schools. It takes part of a French national plan accompanying schools in science and technology (ASTEP Accompagnement en Sciences et Technologie à l'École Primaire). "Girls who..." is also a girl collective that develops and maintains a practicum of sciences, called the factory. "Girls who..." have a double goal: to set an example of sciences by women and to support the practice of sciences for elementary school pupils.

Scratch is an open-source environment for multi-media creation (https://scratch.mit.edu) young people 8 to 16 years old. The Scratch language is made of blocks, arranged in categories. Series of connected blocks form scripts. Categories Motion and Pen allow the displacement of sprites in a scene (a Cartesian coordinate system) and the layout of geometrical and artistic figures. Categories Data, Control and Operators provide typical primitives of imperative programming languages. Sensing category handles inputs/outputs and manages the usual peripherals: mouse, keyboard, webcam, and clock. Events category allows event-driven programming and a parallel way of thinking. Categories Looks and Sound provide the user with multi-media blocks.
The Essence kernel [1] issued from SEMAT initiative [2] helps to assess projects progress and health. Essence yields an actionable and extensible kernel of universal elements, called alphas. Each alpha has a specific set of states that codify points along a progress dimension addressed by the alpha [3].

The first round of "girls who..." produced introductory courses for Scratch, some courses based on the history of Charlie and the chocolate factory [4]. Exemplary lessons have been tested in five elementary schools around Brest, France. The development and the delivery of the course were performed in five sprints using Trello boards. After sprints, we performed an Essence assessment, presented in this paper, which revealed several weaknesses of the project and helped to improve the facility. Essence was chosen because we share the SEMAT concerns: to refund software engineering based on a solid theory, proven principles and best practices.

Section II describes the project according to alphas of Customer and Solution areas of concern: opportunities, stakeholders, requirements and software system. After having discussed time, space, actions and matter of "girls who..." section III presents the Endeavor area of concern: work, team and way-of-working. Finally, section IV concludes.

\section{Assessment of A Project Progress And Health}

A unique feature of the Essence kernel is the way that it handles "things we always work with" through alphas. An alpha is an essential element of the software engineering endeavor - one that is relevant to an assessment of its progress and health. Alphas move through a set of states. Each state has a checklist that specifies the criteria needed to reach the state.

\section{A. Opportunity}

In France, the 2016 reform for elementary and secondary schools defined a common grounding of knowledge, skills and culture, structured in five areas [5]. The common grounding acts as a reference for the school curriculum from 6 to 16 years. Learning Scratch programming and algorithmic thinking was introduced into the "languages to think and communicate" area. According to its authors [6], Scratch is a 
creative design environment that appeals to people who hadn't imagined themselves as programmers. As a technological tool, it supports the learning of many skills of the common ground.

Since 1996, within the framework of the ASTEP, scientific students accompany primary school teachers during science and technology lessons. This accompaniment associates the teacher, the scientific student and pupils around the scientific and technological practice, for a mutual enrichment and natural division of competences.

In Brest University, each second year student of any Bachelor of Science degree attends a course about her/his "Preparation to professional life" with an internship. Students' objectives have two points, regarding her/his professional integration: 1 - the student must carry out a task or a set of specific tasks inside the internship organization or company; 2 - the student must be able to show her/his understanding of a professional environment. For students considering a teacher or an academic career, the ASTEP is a unique opportunity to experiment the teaching situation and area of concern.

In Western countries, there is girl disaffection for STEM area (Science, Technology, Engineering, and Mathematics). However, new generations of students are easily investing in communication and information technologies and appreciate the ludic and creative aspects of Scratch. The "girls who..." facility allows elementary schools to be technologically accompanied in Scratch by second year Bachelor girls. Students are demonstrating an example of sciences by women to the elementary school pupils.

Combination of a) Scratch introduction in the elementary school, b) existence of the French ASTEP program and c) commitment of second year students in the "Preparation to professional life" course establishes an identified opportunity. It corresponds to the first progress level of alpha Opportunity [1, Table 8.3 - Checklist for Opportunity]: the idea is clear and the stakeholders (detailed in the following section) are identified and interested.

The second level for the alpha Opportunity is to have a solution needed. In our facility, "girls who..." participation is made of three distinct activities: design and realization of science or technology learning sessions (based on Scratch); deliver learning sessions in the elementary schools; participate to a scientific project with primary schools class under the responsibility of a $\mathrm{PhD}$ female student. The whole facility is called the factory, and constitutes the solution. All items of the checklist Solution Needed of alpha Opportunity [1, Table 8.3 - Checklist for Opportunity] are not achieved yet: although the need for a solution is confirmed and that a first solution is identified and suggested, the needs for the stakeholders are not entirely established and all problems and their root causes are not completely identified.

\section{B. Stakeholders}

As mentioned in the previous section, second year students have to perform a practical experience through an internship and gain the associated course credits. Parallel to their research work, $\mathrm{PhD}$ students have also to gain credits. With primary education pupils, three groups are part of an example chain towards scientific professions. Each group has a role in the factory:

- Apprentices: elementary school pupils (girls and boys) who are learning Scratch and performing projects.

- Workers: second year female students of any Bachelor of Science program who like to prepare Scratch exercises and examples, deliver learning sessions to apprentices and accompany teachers.

- Tutors: PhD female students who animate science project for apprentices with workers' help and who might assist workers on their disciplinary learning.

Several categories of Ministry of National Education employees are also stakeholders. Educational institution employees, called resource persons, provide the factory with various services. Elementary school teachers engage their class in Scratch learning and science projects. School district inspectors (inspecteurs de circonscription, in French) are teachers' supervisor; they agree students' participation in schools and represent the institutional guarantee. Inside the university, heads of bachelors of science degree and $\mathrm{PhD}$ advisors facilitate students' participation as "girls who..."

Stakeholders groups are identified, key stakeholders are represented and responsibilities are defined; one reached the first alpha level: stakeholders are recognized [1, Table $8.2-$ Checklist for Stakeholders]. The second level is to have stakeholders represented. In the "girls who..." facility, the stakeholders' representatives are authorized and responsibilities are agreed. As detailed in section III.C, the collaborative approach is largely agreed. Consequently, to achieve the second level, the remaining task is to ensure that way-of-working is supported and respected.

\section{Requirements}

"Use cases have been around for almost 30 years as a requirements approach and have been part of the inspiration for more recent techniques such as user stories [7]." Some stories are presented below.

A resource person creates, on a Trello board, a schedule list for a school, then a card for each learning sequence where $\mathrm{s} /$ he seizes sequence description, fills the expiry date and allocates the workers.

A worker consults a Trello board related to daily tasks, decides to take again the realization of a sequence and consults the task card. She downloads the Moodle resources associated with the card, works on the instructions and the project, and updates the Moodle resources.

A worker arrives in a school to animate a learning sequence. She connects herself to Moodle and set up resources for the sequence on each work station. She starts the presentation of the sequence. Once apprentices are working, she explains the work to be carried out using the presentation and supervises the apprentices' activities.

An apprentice starts working. S/he chooses one activity on her/his current sequence. Then, s/he loads the related Scratch project and get on the task. 
All stakeholders are not familiar with requirements engineering. The choice of "user stories" for sketching the requirements makes it possible to communicate them and to effectively share them between the stakeholders. User stories are represented using cards, called story cards, which constitute the smallest grain of requirements. As noted by [8], story cards and tasks to be implemented together with the wall where they are displayed are two tangible artefacts of the distributed knowledge of the team.

The need for a facility such as the factory has been agreed by stakeholders. Users (pupils) are identified. Funding and opportunity are clear. The first level for alpha Requirements is reached [1, Table 8.4 - Checklist for Requirements]: requirements are conceived.

The second level aims to have requirements bounded. Workers and tutors are main stakeholders involved in factory development. All stakeholders agree on the factory purpose Scratch learning - and the factory will be successful if apprentices learn effectively. The stakeholders have a shared understanding of the ASTEP program. Requirements are managed using a Trello board, with a list for each user stories made of pieces materialized by story cards. Assumptions about the system changed (see next section) but are now clearly stated. We are struggling with two items of the Requirements bounded checklist: is the prioritization scheme clear; are constraints identified and considered? In the short history of "girls who..." each new school joining the factory brought new circumstances and new needs, and workers adapted consequently requirements. In order to move to the third level - Requirements coherent - one needs to find a way to manage new constraints and prioritize requirements.

\section{System}

The initial idea behind the system was to build an online training of Scratch. The first source of inspiration was the web site code.org. It offers many well-organized activities from simple to complex in terms of teaching programming. Kalelioglu studied the effects of learning programming with code.org regarding reflexive thought, problem resolution, and gender issues. She stated: "Students developed a positive attitude towards programming, and female students showed that they were as successful as their male counterparts, and that programming could be part of their future plans [9]."

During preliminary discussions with elementary school teachers and inspectors, the need moved from a remote on-line course to classroom training sessions. The first round of "girls who..." established the proof of concept thanks to five elementary schools. We kept the code.org principle of learning sequences divided into increasingly complex activities. Strength of code.org is an integrated environment, providing the user with learning instructions, a workspace where you can do programming, on-line help and feedback with learning. This integration remains a requirement of the system, but in a future version. Moreover, some learning sequences use small robots called mbot. Robotics programming is performed in the mblock environment, an open-source Scratch extension.

The architecture of the system is thus made up of:
- Several Trello boards (https://trello.com).

- Prezi presentations (https://prezi.com).

- A Moodle server from Brest University, dedicated to online courses and accessible by external users (https://moodlespoc.univ-brest.fr).

- School computers or tablets with Scratch and mblock.

The architecture selection criteria have been agreed on, hardware platforms identified and technologies selected. System boundary is known and key technical risks agreed to. Significant decisions about the system have been made: opensource software and free contents. All criteria of the first level for alpha System are fulfilled [1, Table 8.5 - Checklist for System Software] and the architecture is selected.

The second level is to have a demonstrable system. According to the checklist associated with this level, one needs to demonstrate architectural characteristics, critical hardware, critical interfaces and integration with other existing systems. One needs to exercise the system and measure its performance. Then the relevant stakeholders will agree that the demonstrated architecture is appropriate. All verifications and measurements will be realized in the next round where "girls who..." will run courses in many schools; the goal is to demonstrate that the architecture of the system is fit for purpose and supports testing.

\section{THE ENDEAVOUR AREA OF CONCERN}

The Endeavour area of concern contains everything to do with the team, and the way that they approach their work. Endeavour contains three alphas: Team, Work and Way-ofworking. Key aspects of the facility are presented: time, space, actions and matter then alphas' assessment is drafted.

\section{A. Time of girls who...}

Each year, "girls who..." will welcome new workers (second-year students) and new tutors (starting PhD students).

"Girls who..." go in schools and have three kinds of contributions: Scratch discovery sessions (in May/June), Scratch learning sequences (from October to February), and science project accompaniments (from March to June). A Trello board equivalent to the product backlog, called the service backlog, contains a list by school. Each school visit is materialized by a card and its attributes: date, members, checklist, and resources.

During her first period in the factory (1-4 weeks, see sections II.A and III.D), each worker produces contents that will be integrated in one of the factory courses. Workers work in pair and the time unit is the week: the product backlog (a Trello board) contains a list per week. The list keeps cards (tasks or sequences in schools) organized in their various stages of progress.

\section{B. Spaces of girls who...}

The factory managed by "girls who..." is a common property (like Wikipedia or an open-source software) under a double license, GNU GPL and CC BY-SA. 
Digital spaces of the project are numerous: Moodle courses and Prezi presentations, product and service backlogs. The entry point is a public Trello board, in French (https://trello.com/b/83omDwmt/les-filles-qui).

The integration of new workers in the factory occurs during the first internship (1-4 weeks) in the facility. Thanks to a partnership with an engineer school, École Nationale Supérieure de Techniques Avancées - ENSTA Bretagne, new workers are accommodated in a dedicated room at ENSTA Bretagne. Thereafter, "girls who..." will not be always on the same space-time: girls telework, go in schools by pairs, exchange synchronously and asynchronously. However, this integration space-time where "girls who..." meet presentially is a key element of network dynamics. It makes it possible to acquire tools and methods usage which will be then used remotely. A distributed common facility such as our factory has to schedule gathering space-time events throughout the year to keep girls trained, to strengthen network membership and to ensure continuity between presence and distance.

\section{Actions of girls who...}

"Girls who..." work is ruled by two key principles: setting an example of science and gender equality. "Girls who..." act and are models for other girls who act and so on.

A worker achieves various tasks. She contributes to the facility organization and digital spaces management. She designs and realizes learning sequences for Scratch, Scratch junior, mbot programming and carry out assessments. She accompanies elementary school classes within the national program ASTEP (see section II.A), either delivering learning sequence or participating to science projects. She contributes to a research action endeavor related to the introduction of programming and algorithmic thinking in elementary schools. A tutor achieves targeted action. Upon teachers' request, she leads science projects for elementary school pupils. She might assist workers during their Bachelor studies.

\section{Matter of girls who...}
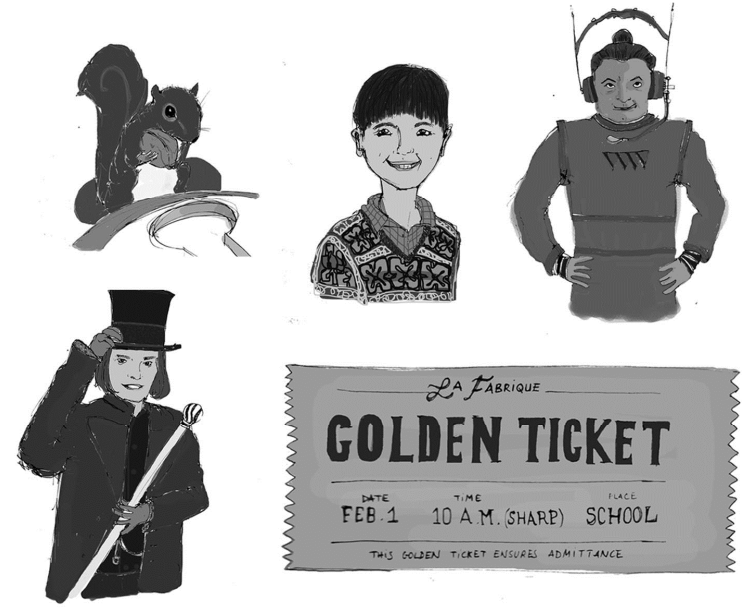

Fig. 1. Illustrations by Lisa, inspired by "Charlie and the chocolate factory" the novel by Roald Dahl and the eponym movie by Tim Burton.
At the end of the first round, three courses has been developed and partly tested: a 6-sequence course of Scratch programming for 10-12 years, a 6-sequence course (sharing a few sequences with the previous course) of mbot robots programming for 10-12 years, a 3-sequence introductory course of Scratch junior for 6-8 years. Scratch courses use characters inspired of the book "Charlie and the chocolate factory" of Roald Dahl [4].

\section{E. A first endeavor}

During the first five-weeks round, nine workers realized the programming courses described above and are co-authors of this paper. Whereas the initial idea was to prepare courses for next year, it has been quite clear that "girls who..." need to test courses in schools. Generally speaking, the design, the realization and courses delivery occurred in short cycles (one week) and built incrementally, the next week incorporating the current week feedback. A regular health evaluation of alphas Work and Team guided the project progress. The alpha Wayof-Working was barely assessed.

\section{1) Work.}

A Trello board was used for definition, planning and assignment of tasks: a list per week and a card per workday with workers present this day. Card descriptions were informal, but for recurring tasks, helped to feed various to-do lists. The lists, as indicated in the section III.A, control tasks and schools' accompaniments and constitute the product backlog and the service backlog of the project.

Required results, constraints, funding sources and priorities are clear; stakeholders are known; initiators are identified. All criteria of the first level of alpha Work [1, Table 8.7 - Checklist for Work] are met and work is initiated.

The second level is to have the work prepared. Commitment of faculty is made; a credible plan and funding is in place and renewable each year. Resource availability (mainly workers) is understood; cost and effort of the work are roughly estimated. Work is broken down sufficiently in learning sequences for productive work to start; tasks are identified and prioritized; at least one of members (the Science Faculty) is ready. Exposure to the risks is minimal thus one will admit that it is understood. There are two points to fulfill to have the work prepared. Criteria of acceptance have to be established, for instance to constitute pupils cohorts and to perform measurements. Integration points have to be defined, in contents terms - how to enrich the poll of courses, and in schools terms - how to insert a new school in the facility.

\section{2) Team.}

Seven workers of the first round came from Bachelor of Mathematics and Bachelor of Informatics. They know each other, some students committed immediately to the project and this was the key to decide the others. The project evolved from an online course to face-to-face courses; however the team mission and composition are now defined; constraints are known; required competences in programming and teaching are identified. Student themselves outlined their responsibilities and the need for a clear level of commitment. 
"Girls who..." initiators received a training intended to animate collaborative projects (http://animacoop.net). Training was carried out part-time over three months. Training facilitated the selection of a distributed and co-operative leadership model. Training helped to set rules of governance which is shared between workers, tutors, heads of Bachelor studies and network animators.

The greatest difficulty arose from the two latter items of the checklist: definition of mechanisms to grow the team and determination of team size. An identified risk is that schools demand increases too fast; during the first round, we selected five pilot schools; for the 2017-2018 academic year, 18 elementary classes are already part of the program. Due to introduction of Scratch into the elementary school curriculum, it can lead to a demand exceeding supply. In French Faculties of Science, biology studies are largely invested by girls, and there is no need for exemplary models for Biology. However "girls who..." make biology can be interested by Scratch technology and by going in the schools as well. We have to evolve in a way that "girls who..." make biology can bring forces to the facility and find an interest for their scientific discipline. This is the goal of science project accompaniments, thus all criteria of the first level of alpha Team are met [1, Table 8.6-Checklist for Team] and team is seeded.

The second level is to have a formed team. Workers know their role and their place in the team; individual and team responsibilities are accepted and aligned with competencies. As volunteers, members accept work and it was underlined in the previous section that members must commit to the work and the team. Team communication mechanisms have been defined: Trello for backlog, planning and tasks and Moodle as a Learning Management System. "Girls who..." use Slack as instant messaging and Loomio for collective decision making. The unknown factor relates to the growth: will be enough workers available and did we fail to identify external collaborators? The points will be addressed at the next round.

\section{3) Way-of-working}

The first level of alpha Way-of-Working is to have principles established [1, Table 8.8 - Checklist for Way-OfWorking]. The criteria are: the team actively supports the principles, the stakeholders agree with principles, the needs for tool are agreed, the approach is recommended, the operational context is understood and the constraints of practice and tool are understood.

The first round of "girls who..." did not have established principles before its start, but workers defined their way-ofworking and made the following decisions. A pair of workers is assigned to a school; design and realization of learning sequences of training is assigned individually; Prezi presentations are used to present learning instructions and exercises interactively with pupils; Slack, Trello and Loomio usage rules are defined; tools and resources required to be available in schools are identified; a back-up solution is needed and implemented, for content availability as well as for software tools. Foundations are laid and at the next round, we will see if the new "girls who..." will follow these principles. We will check if the first level is reached and principles established.

\section{CONCLUSION}

The first round of "girls who..." shaped a facility with a double goal: to set the example of "girls who..." do sciences and technology and to support the introduction of Scratch and algorithmic thinking in the elementary schools. "Girls who..." prepared Scratch lessons, delivered courses in five pilot schools and organized the system for next rounds. Kids loved when "girls who..." came in schools and learned Scratch and robots programming with enthusiasm. For 2017-2018 year, 18 elementary classes are already part of the program.

The facility evolved considerably since we wrote initial specifications nine months ago. The facility was led with a double help: training intended to animate collaborative projects and use of the Essence kernel to assess the state of different areas of concern and to define next steps to complete.

Essence provides an understanding of the progress and health of development efforts and how practices can be combined into an effective way of working. The use of Essence can help teams, among others, to detect systemic problems early and take appropriate action; evaluate the completeness of the set of practices selected, and understand the strengths and weaknesses of the way of working; keep an up-to-date record of the team's way of working, and share information and experiences with other teams [10]. Essence assessment gave us a clear vision of the project state and raised critical weaknesses of the facility. Indeed, we are using Essence to assess our research projects health and progress.

\section{Acknowledgments}

Many persons facilitated the birth of "girls who..." including Pascale Huret-Cloastre, Hélène Klucik, Isabelle Queré, Corinne Tarits, Yann Ti-Coz.

\section{References}

[1] Object Management Group, Essence - Kernel and Language for Software Engineering Methods, Version 1.1, OMG Document Number: formal/2015-12-02, URL: http://www.omg.org/spec/Essence/1.1, 2015 (last accessed 2017/09/21).

[2] I. Jacobson et al. "The essence of software engineering: the SEMAT kernel," Queue 10.10, 2012, pp. 40-49.

[3] I. Jacobson, E. Seidewitz, "A new software engineering," Communications of the ACM 57(12), 2014, pp. 49-54.

[4] R. Dahl, Charlie et la chocolaterie. Gallimard, Paris, 1978.

[5] Ministère de l'éducation nationale, Le socle commun de connaissances, de compétences et de culture http://www.education.gouv.fr/cid2770/lesocle-commun-de-connaissances-et-de-competences.html (last accessed 2017/09/21).

[6] M. Resnick et al. "Scratch: programming for all," Communications of the ACM, 52(11), é009, pp. 60-67.

[7] I. Jacobson, I. Spence, I. and B. Kerr, "Use-case 2.0," Communications of the ACM, 59(5), 2016, pp. 61-69.

[8] H. Sharp, H. Robinson, J. Segal, and D. Furniss, "The Role of Story Cards and the Wall in XP teams: a distributed cognition perspective," Agile Conference, 2006, pp. 11.

[9] F. Kalelioğlu, "A new way of teaching programming skills to K-12 students: code.org," Computers in Human Behavior 52, 2015, pp. 200210 .

[10] I. Jacobson, I. Spence, I., and P. W. Ng, "Agile and SEMAT: perfect partners," Communications of the ACM, 56(11), 2013, pp. 53-59. 
